OPEN ACCESS

Edited by:

Huanfa Yi,

Jilin University, China

Reviewed by:

Kawaljit Kaur,

University of California, Los Angeles,

United States

Yuzhu Hou,

University of Chicago, United States

*Correspondence:

Yuxia Wang

lily31415926@126.com

Specialty section: This article was submitted to

Cancer Immunity and Immunotherapy,

a section of the journal

Frontiers in Immunology

Received: 30 September 2020

Accepted: 06 November 2020

Published: 25 January 2021

Citation:

Wang Y (2021) Advances in Hypofractionated Irradiation-Induced

Immunosuppression of Tumor

Microenvironment.

Front. Immunol. 11:612072. doi: 10.3389/fimmu.2020.612072

\section{Advances in Hypofractionated Irradiation-Induced Immunosuppression of Tumor Microenvironment}

\author{
Yuxia Wang * \\ Department of Radiation Oncology, Peking University Third Hospital, Beijing, China
}

Hypofractionated radiotherapy is external beam irradiation delivered at higher doses in fewer fractions than conventional standard radiotherapy, which can stimulate innate and adaptive immunity to enhance the body's immune response against cancer. The enhancement effect of hypofractionated irradiation to immune response has been widely investigated, which is considered an approach to expand the benefit of immunotherapy. Meanwhile, increasing evidence suggests that hypofractionated irradiation may induce or enhance the suppression of immune microenvironments. However, the suppressive effects of hypofractionated irradiation on immunomicroenvironment and the molecular mechanisms involved in these conditions are largely unknown. In this context, we summarized the immune mechanisms associated with hypofractionated irradiation, highlighted the advances in its immunosuppressive effect, and further discussed the potential mechanism behind this effect. In our opinion, besides its immunogenic activity, hypofractionated irradiation also triggers homeostatic immunosuppressive mechanisms that may counterbalance antitumor effects. And this may suggest that a combination with immunotherapy could possibly improve the curative potential of hypofractionated radiotherapy.

Keywords: hypofractionated irradiation, immunosuppression, tumor, immune microenvironment, radiotherapy

\section{INTRODUCTION}

Radiation therapy (RT) is the mainstay of treatment in cancers, and up to 50\% of cancer patients receive radiotherapy to improve local control, survival, or quality of life (1). Conventional fractionated radiotherapy usually delivers in small fractions (1.8-2.0Gy per fraction) over a number of weeks, while hypofractionated radiotherapy delivers higher dose (3-20Gy) in fewer fractions $(2,3)$. Emerging evidence suggests that hypofractionated radiotherapy-clinically called stereotactic body radiotherapy (SBRT) or radiosurgery (SRS) - may elicit a pronounced anti-tumor effect $(4,5)$. In addition to directly killing tumor cells, hypofractionated irradiation can induce tumor cells death via antitumor immunity (6) and vascular damage (7). There are two types of RTinduced nontargeted effects: (1) the bystander effect, which describes the additional regression of nonirradiated surrounding tumor sites after local radiation therapy $(8,9)$, and $(2)$ the abscopal effect, which describes the tumor regression of distant unirradiated tumor site $(10,11)$. Preliminary 
studies suggest that radiation-induced immune responses are probably dose-dependent $(12,13)$. Substantial work has demonstrated that the nontargeted effects are attributed to the interaction between tumor irradiation and the host immune system $(14,15)$.

The tumor microenvironment (TME) is the stroma surrounding cancer cells that modulates the progression of cancer $(16,17)$. The TME consists of immune cells, tumor blood vessels, fibroblasts, and epithelial cells (18-21). Immune cells-such as tumor-associated macrophages (TAMs), tumorassociated neutrophils (TANs), myeloid-derived suppressor cells (MDSCs), mast cells, and natural killer (NK) cells-can produce a variety of factors (chemokines, cytokines, and enzymes) that directly or indirectly act as initiator or coordinator of the cellular immune responses to irradiation. Among all the stromal cells present in the TME, cancer-associated fibroblasts (CAFs) are one of the most abundant components of the tumor mesenchyme, which play a key role in promoting or retarding tumorigenesis in a context-dependent manner (22). In addition, radiotherapy may induce vascular damages or stimulate angiogenesis according to different regimens (23).

A large number of studies have shown that hypofractionated radiotherapy exerts a stimulating effect on the anti-tumor immune responses by inducing tumor cell death, normalizing aberrant tumor vasculature, releasing tumor associated antigens (TAAs) and inflammatory cytokines (24, 25). However, preclinical studies in some tumor models have suggested that radiotherapy-induced changes in the TME may induce an immunosuppressive TME, which may promote tumor invasion and spread in some situations $(26,27)$.

In this review, we summarized the immune mechanisms associated with hypofractionated radiotherapy, highlighted the advances in its immunosuppressive effect, and further discussed the potential mechanism behind this effect.

\section{HYPOFRACTIONATED IRRADIATION INFLUENCES IMMUNOLOGICAL RESPONSES}

Higher physical or biologic dose is associated with better local control and with better survival in some cases (28-30). In clinical practice, a typical example of hypofractionated radiotherapy is stereotactic body radiation, which delivers one to five fractions of doses above 6Gy per fraction to small target volumes (31). SBRT achieved high local control in the treatment of many cancers, such as early lung cancer, brain metastases, spinal metastases, and so on. The excellent efficacy of SBRT mainly attributed to the precisely delivered high dose to tumor site and the minimized dose to adjacent normal tissue. Besides this, SBRT can induce tumor cell death and tumor size reduction in non-radiotherapy sites, named bystander effect and abscopal effect (8-11).

The radiobiological mechanisms of hypofractionated radiotherapy are largely different from that of conventional radiotherapy. The reoxygenation, repopulation, repair, and redistribution (4Rs) are important components in the response of tumor to conventional fractionated radiotherapy $(32,33)$, and tumor cells are killed directly through irreparable DNA doublestrand breaks in the forms of mitotic catastrophe and cellular apoptosis (34). Low-dose irradiation induces DNA damage and initiate apoptosis by activation of p53-dependent mechanisms, upregulating plasma membrane death receptor, and activation of the pro-apoptotic SAPK/JNK pathway $(35,36)$. However, in the setting of high dose irradiation, tumor cells may be eliminated in the form of necrosis (32). Necrosis is considered an immunogenic pathway and often accompanied by the release of pro-inflammatory cytokines and damage-associated molecular patterns, which promote tumor cell killing by anti-tumor T cell response (37).

Hypofractionated radiotherapy may change the tumor cell phenotype and the tumor microenvironment. After hypofractionated irradiation, tumor cells demonstrate increased cell-surface expression of immunogenic molecules, such as adhesion molecules, death receptors, stress-induced ligands, heat shock proteins, and stimulatory molecules (such as MHC-I and CD80) $(38,39)$. These immunophenotype changes make human tumors more amenable to be recognized by immune system and more sensitive to T cell-mediated cytotoxicity (40). Additionally, pro-inflammatory molecules and danger signals increase in the tumor microenvironment (41-43). Immune cells, such as CD8+ T cells and dendritic cells, are activated and recruited into the tumor and play an important role in anti-cancer immunity (44).

\section{TME PLAYS A CENTRAL ROLE IN RESPONSE TO RADIOTHERAPY}

The tumor microenvironment is the internal environment which tumors depend on survival and development. TME is associated with tumor growth, progression, and metastasis $(16,17)$. Cancer is an extremely complex and heterogeneous disease. Cancer cells present distinct features and various mutations, which is an important clinical determinant of patient outcomes. Dynamic changes occurring in the TME cause tumor cell variants selection, which may promote the complexity of cancer heterogeneity and impact the response to different treatment strategies $(45,46)$.

The TME consists of tumor stroma cells, immune cells, and a variety of factors produced by these cells (chemokines, cytokines, and enzymes) (47-49). Tumor stroma cells include cancerassociated fibroblasts, epithelial cells (ECs), and mesenchymal stromal cells (MSCs). CAFs are the most abundant cells in TME and play an important role in angiogenesis and tumor growth after irradiation (22). The damage of ECs has been shown to be a major factor in the biological mechanism in response to SBRT $(50,51)$. Cells of the immune system include tumor-associated macrophages, tumor-associated neutrophils, myeloid-derived suppressor cells, natural killer cells (NKs), T cells, B cells, dendritic cells (DCs), and mast cells. These cells significantly differ in radiosensitivity. In general, NKs and B lymphocytes are the most radiosensitive immune cells, while DCs, CAFs, and ECs are more radioresistant cells (27). Among the immune cells, regulatory T cells (Tregs) are more radioresistant than any other kinds of T cells (such as CD8+ T 
cells) and B cells (27). As a result, the response of TME after irradiation varies according to the dose and fractionation schedule, which causes different outcomes in different cell types in TME.

Radiotherapy is a double-edged sword that can activate or suppress the immune response of TME under different conditions. The "hot" TME refers to a "inflamed" phenotype with highly infiltration of $\mathrm{T}$ cell lymphocytes $(52,53)$. Typical features for a hot TME include high number of effector cells (NK cells, CD8+ T cells, and Th1 cells) and functional antigen-presenting cells (APCs), and TAMs with the M1 phenotype. On the contrary, the "cold" TME refers to a "noninflamed" phenotype lack of T cell lymphocytes infiltration $(52,53)$. Characteristics of a cold TME include high numbers of Treg cells and MDSCs, lack of effector cells, and enrichment of immunosuppressive cytokines $(47,54)$. Activated NK cells and CD8+ T cells can eliminate tumor cells, while immunosuppressive TME is associated with enhanced metastasis and poor prognosis in patients $(55,56)$. Currently, it is not fully understood what dose and fractional radiotherapy induces the immune activated TME, and what dose and fractional radiotherapy causes the immunosuppressive TME.

\section{HYPOFRACTIONATED IRRADIATION INDUCES ANTI-TUMOR IMMUNE RESPONSES}

Emerging evidence demonstrates that hypofractionated radiotherapy can induce a pronounced anti-tumor effect ((5762), Figure 1). The immunoreactive effect of radiation therapy is dose-dependent, and preclinical studies revealed that more than $8-10$ Gy per fraction are more effective in enhancing the anti- tumor immune response (63). In addition to the direct killing effects, hypofractionated radiotherapy can induce immunogenic death of tumor cells and orchestrate a spectrum of cellular and molecular alterations in the anti-tumor immune response (64).

After high-dose irradiation, cellular and DNA damage facilitate the generation and release of tumor-associated antigens, while necrosis or apoptosis cancer cells can generate pro-inflammatory "danger" signals and damage associated molecular patterns (DAMPs) $(24,62,65)$. DAMPs and "danger" molecules stimulate dendritic cells via toll-like receptors (TLRs), and facilitate the uptake of TAAs and their presentation on major histocompatibility complex class 1 (MHC-1) to activate the tumor-specific cytotoxic $\mathrm{T}$ lymphocytes $(24,66)$. Dendritic cells are the major antigenpresenting cell that can process antigenic materials and present TAAs to CD8+ T cells (57, 65-67). Many preclinical studies have demonstrated that hypofractionated irradiation can increase presentation of TAAs to CD8+ T cells and enhance the antitumor T-cell-mediated immune response (68).

Irradiation also increases MHC-I expression by tumor cells, which presents TAAs to specific cytotoxic T cells, leading to the lysis of tumor cells (69). Garnett et al. (70) reported that, when irradiated by a single dose of 10-20Gy, colon and lung cell lines up-regulated the expression of MHC-I, while all of 4 prostate cancer cell lines did not. These results may suggest that the antitumor immunity response induced by hypofractionated radiotherapy differs among different cancer types.

In addition, radiation therapy exerts an immunostimulating activity by increasing NK cell cytotoxicity, facilitating the infiltration and accumulation of CD8+ $\mathrm{T}$ cells and tumorassociated M1 macrophages (inhibiting tumor growth), reducing the infiltration of Tregs (71), enhancing the

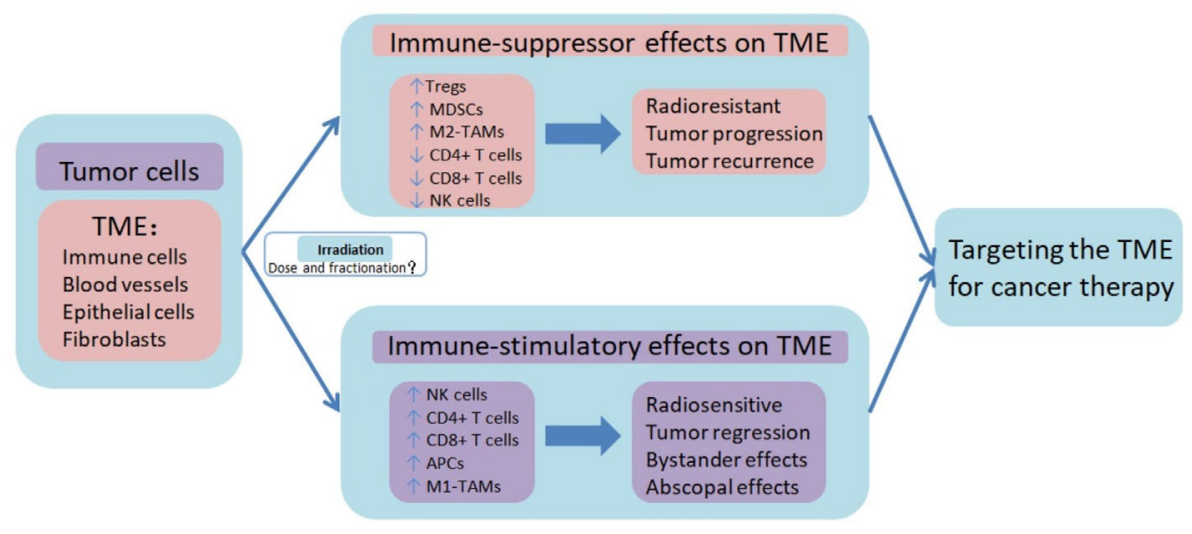

FIGURE 1 | Immune-suppressor effects and immune-stimulatory effects of radiotherapy on tumor microenvironment. Radiotherapy, especially hypofractionated irradiation, contributes to the induction of anti-tumor immune responses, which promote tumor control. Besides the immune-suppressor effects, radiotherapy also induces immunosuppression of TME, resulting in tumor progression and recurrence. The high infiltration of T cell lymphocytes in TME, known as immune hot or inflamed phenotype, is characterized by high number of effector cells (NK cells, CD8+ T cells, and Th1 cells) and functional antigen-presenting cells (APCs), and TAMs with the M1 phenotype. On the contrary, the lack of T cell lymphocytes infiltration in TME, known as immune cold or noninflamed phenotype, is characterized by high numbers of Treg cells and MDSCs, lack of effector cells, and enrichment of immunosuppressive cytokines. However, it is not fully understood what dose and fractional radiotherapy induces the immune activated TME, and what dose and fractional radiotherapy causes the immunosuppressive TME. Combination therapy targeting TME may help to improve the therapeutic benefit of radiotherapy. TME tumor microenvironment, Tregs regulatory T lymphocytes, MDSCs myeloid-derived suppressor cells, M2-TAMs tumor-associated M2 macrophages, NK cells natural killer cells, APCs antigen-presenting cells, M1-TAMs tumor-associated M1 macrophages. 
expression of Fas and IFN- $\gamma$, and inhibiting the PD-1/PD-L1 pathway $(24,27)$.

Clinical evidences of the effect of radiation on TME include bystander effect and abscopal effect, in which local irradiation can induce regression in non-irradiated tumor or metastasis. Clinical reports of bystander or abscopal effects induced by radiation alone are relatively rare, and these phenomena are mainly observed in relatively high-dose radiotherapy (10). Tubin et al. $(8,9,72,73)$ conducted a series studies to explore the by stander and abscopal effects in unresectable stage IIIB/IV bulky non-small cell lung cancer (NSCLC), which were inoperable or unsuitable for radical radio-chemotherapy. They delivered 1-3 fractions each of $10-12$ Gy to $30 \%$ of the bulky tumor. As a result, they observed that the bystander and abscopal effects induced by partial irradiation were $95 \%$ and $45 \%$ (8), respectively. Furthermore, partial irradiation improved survival and tumor control compared to the standard of care. The researchers speculate that the induction of the bystander and abscopal effect are attribute to the irradiation to the hypoxic clonogenic cells and the sparing of peritumoral immune microenvironment and regional circulating lymphocytes. These results imply that irradiating a partial tumor may be enough to initiate immune modulation.

\section{HYPOFRACTIONATED IRRADIATION INDUCES IMMUNOSUPPRESSIVE TME}

Preclinical studies have suggested that irradiation-induced changes in tumor microenvironment may favor tumor growth, promoting tumor invasion and metastasis $((74,75)$, Figure 1). This issue must be taken seriously, because suppression of the immune microenvironment not only leads to worse prognosis, but it may also be a legitimate therapeutic target.

Radiotherapy could eliminate radiosensitive immune cells, while radioresistant immune cells survive from it, thereby changing the proportion of immune cells in TME and causing suppression of the immune microenvironment. In the immune system, NK cells are the most radiosensitive immune cells (25, 76). On the contrary, immunosuppressive Tregs and MDSCs are more radioresistant than other population of $\mathrm{T}$ cells $(27,77)$. Kachikwu et al. (78) evaluated the impact of 0,10 , or $20 \mathrm{~Gy}$ irradiation on Treg cells in murine model of prostate cancer. They found that Treg cells are more resistant to radiation than other lymphocytes, resulting in their preferential increase. In addition, Shi et al. (79) demonstrated that local irradiation with 10,20 , or 30Gy in cervical cancer patients significantly decreases CD8+ T cells, while having no effects on Tregs. Similarly, the MDSCs have been shown to accumulate in TME and suppress the activation of CD4+ and CD8+ T-cells $(80,81)$. Therefore, after certain doses and fractionated irradiation, NK cells and CD8+ T cells with anti-tumor effects are eliminated, while Treg cells and MDSCs with immunosuppressive effects are left. Changes in the types and numbers of immune cells result in the TME transformation from sensitive to resistant for response to radiotherapy (27).
High dose irradiation induces tumor vascular damage, which limits the infiltration of cytotoxic T lymphocytes into the tumor and increases the area of hypoxia $(82,83)$, leading to the resistance to radiotherapy $(84,85)$. Tumor blood vessels are more permeable and morphologically immature, and they are more sensitive to radiation (86). Vascular destruction is mainly observed at dose greater than 5 to $10 \mathrm{~Gy}(27,87)$, which drastically reduces the blood flow and induces hypoxia. Sonveaux et al. (88) reported that irradiation by a $6 \mathrm{~Gy}$ dose up-regulates the expression and activity of endothelial nitric oxide synthase (eNOS). This activates the nitric oxide (NO) pathway in ECs and generates tumor angiogenesis. The process of vasculogenesis leads to the recruitment of radioresistant suppressor cells, including MDSCs, Tregs, and TAMs with the M2 phenotype $(87,89)$.

CAFs are the most abundant cells in the tumor stroma and play an important role in tumor angiogenesis, growth, and metastasis (90-94). CAFS are radioresistant, being able to survive at doses of up to 50Gy (95-97). CAFs can stimulate the recruitment of cells, which promotes tumor blood vessel formation and facilitates tumor recurrence $(98,99)$. The CAFs also secrete enzymes such as matrix metalloproteinases, which degrade the extracellular matrix, promote the migration of CAFS, and facilitate the invasion of tumor cells $(90,100)$. Furthermore, in vitro studies have demonstrated that a dose $>10$ Gy to fibroblasts induces an irreversible senescent phenotype. Metabolically activated CAFs release growth factors, proteolytic enzymes, and cytokines, inducing an environment that promotes tumor growth and spread $(82,96,101-103)$. However, the cancer promoting effects of senescent fibroblasts may depend on the dose and fraction of radiotherapy and vary in different tumor types (104).

Understanding the immunosuppressive effects of hypofractionated radiotherapy on the TME may help to explore new treatment strategies to block the immunosuppressive responses of radiotherapy and augment the antitumor effects (105). Previous studies suggested that both enhancing the function of tumor suppressor cells and inhibiting the function of tumor promoting cells could improve the therapeutic efficiency of radiotherapy (106-109). For example, the combination of radiotherapy and immunotherapy may prevent early exhaustion of anti-tumor immunity by boosting the activation of NK cells and cytotoxic T lymphocytes $(106,107)$. Moreover, inhibiting the immunosuppressive cells like Tregs, MDSCs, and TAMs can induce durable anti-tumor immunity and prevent tumor progression. A previous study by $\mathrm{Xu}$ et al. (108) showed that inhibition of macrophage colony-stimulating factor CSF-1 could reduce the recruitment of both TAMs and MDSCs, thereby suppressing tumor growth more effectively than irradiation alone. Furthermore, vascular-targeted agents are demonstrated to alter the tumor microenvironment to increase the radiosensitivity of tumor (110). Targeting the tumor immune microenvironment is an interesting strategy to enhance the efficacy of radiotherapy, and much remains to be investigated before realizing its potential therapeutic effects clinically. 


\section{DISCUSSION}

Recent technological advances in external beam radiotherapy have allowed larger doses per fraction delivered to tumor, while minimizing doses to normal tissues adjacent. However, despite the increasing effectiveness of hypofractionated radiotherapy, we still can't completely avoid tumor recurrence and progression. A large number of studies have shown that hypofractionated radiotherapy can induce immune-activated TME and improve treatment efficacy. However, increasing studies have suggested that hypofractionated radiotherapy can promote immunesuppressive TME and play a significant role in radioresistance and tumor recurrence. There is a delicate balance between TME suppression and activation triggered by hypofractionated

\section{REFERENCES}

1. Sato H, Okonogi N, Nakano T. Rationale of combination of anti-PD-1/PDL1 antibody therapy and radiotherapy for cancer treatment. Int J Clin Oncol (2020) 25:801-9. doi: 10.1007/s10147-020-01666-132246277

2. Frey B, Ruckert M, Weber J, Mayr X, Derer A, Lotter M, et al. Hypofractionated Irradiation Has Immune Stimulatory Potential and Induces a Timely Restricted Infiltration of Immune Cells in Colon Cancer Tumors. Front Immunol (2017) 8:231. doi: 10.3389/fimmu.2017.00231

3. Prasanna A, Ahmed MM, Mohiuddin M, Coleman CN. Exploiting sensitization windows of opportunity in hyper and hypo-fractionated radiation therapy. J Thorac Dis (2014) 6:287-302. doi: 10.3978/j.issn.20721439.2014.01.14

4. Chen Y, Gao M, Huang Z, Yu J, Meng X. SBRT combined with PD-1/PD-L1 inhibitors in NSCLC treatment: a focus on the mechanisms, advances, and future challenges. J Hematol Oncol (2020) 13:105. doi: 10.1186/s13045-02000940-Z

5. Ijsseldijk MA, Shoni M, Siegert C, Wiering B, van Engelenburg A, Tsai TC, et al. Oncologic Outcomes of Surgery Versus SBRT for Non-Small-Cell Lung Carcinoma: A Systematic Review and Meta-analysis. Clin Lung Cancer (2020) S1512-7304(20):30140-6. doi: 10.1016/j.cllc.2020.04.017

6. Chajon E, Castelli J, Marsiglia H, De Crevoisier R. The synergistic effect of radiotherapy and immunotherapy: A promising but not simple partnership. Crit Rev Oncol Hematol (2017) 111:124-32. doi: 10.1016/j.critrevonc 2017.01.017

7. Zhuang H, Zhuang H, Lang N, Liu J. Precision Stereotactic Radiotherapy for Spinal Tumors: Mechanism, Efficacy, and Issues. Front Oncol (2020) 10:826. doi: $10.3389 /$ fonc. 2020.00826

8. Tubin S, Khan MK, Salerno G, Mourad WF, Yan W, Jeremic B. Monoinstitutional phase 2 study of innovative Stereotactic Body RadioTherapy targeting PArtial Tumor HYpoxic (SBRT-PATHY) clonogenic cells in unresectable bulky non-small cell lung cancer: profound non-targeted effects by sparing peri-tumoral immune microenvironment. Radiat Oncol (2019) 14:212. doi: 10.1186/s13014-019-1410-1

9. Tubin S, Ashdown M, Jeremic B. Time-synchronized immune-guided SBRT partial bulky tumor irradiation targeting hypoxic segment while sparing the peritumoral immune microenvironment. Radiat Oncol (2019) 14:220. doi: 10.1186/s13014-019-1423-9

10. Ashrafizadeh M, Farhood B, Eleojo MA, Taeb S, Rezaeyan A, Najafi M. Abscopal effect in radioimmunotherapy. Int Immunopharmacol (2020) 85:106663. doi: 10.1016/j.intimp.2020.106663

11. Chicas-Sett R, Morales-Orue I, Castilla-Martinez J, Zafra-Martin J, Kannemann A, Blanco J, et al. Stereotactic Ablative Radiotherapy Combined with Immune Checkpoint Inhibitors Reboots the Immune Response Assisted by Immunotherapy in Metastatic Lung Cancer: A Systematic Review. Int J Mol Sci (2019) 20(9):2173. doi: 10.3390/ijms20092173

12. Bernstein MB, Garnett CT, Zhang H, Velcich A, Wattenberg MM, Gameiro SR, et al. Radiation-induced modulation of costimulatory and coinhibitory irradiation. We still don't know which doses and fractionation schedule activate the anti-tumor immune response and which induce the immune suppression. Moreover, different sites and types of tumors may respond differently to the same dose and fractionated irradiation. More knowledge is needed to optimize the radiotherapy strategy. Understanding the immune effects of hypofractionated radiotherapy on the TME may help to improve therapeutic benefit and explore new combination therapy strategies.

\section{AUTHOR CONTRIBUTIONS}

YW designed this work and wrote and revised the manuscript.

T-cell signaling molecules on human prostate carcinoma cells promotes productive antitumor immune interactions. Cancer Biother Radiopharm (2014) 29:153-61. doi: 10.1089/cbr.2013.1578

13. Schaue D, Ratikan JA, Iwamoto KS, McBride WH. Maximizing tumor immunity with fractionated radiation. Int J Radiat Oncol Biol Phys (2012) 83:1306-10. doi: 10.1016/j.ijrobp.2011.09.049

14. de Olza MO, Bourhis J, Irving M, Coukos G, Herrera FG. High versus low dose irradiation for tumor immune reprogramming. Curr Opin Biotechnol (2020) 65:268-83. doi: 10.1016/j.copbio.2020.08.001

15. Demaria S, Ng B, Devitt ML, Babb JS, Kawashima N, Liebes L, et al. Ionizing radiation inhibition of distant untreated tumors (abscopal effect) is immune mediated. Int J Radiat Oncol Biol Phys (2004) 58:862-70. doi: 10.1016/ j.ijrobp.2003.09.012

16. Hanahan D, Weinberg RA. Hallmarks of cancer: the next generation. Cell (2011) 144:646-74. doi: 10.1016/j.cell.2011.02.013

17. Mantovani A, Ponzetta A, Inforzato A, Jaillon S. Innate immunity, inflammation and tumour progression: double-edged swords. J Intern Med (2019) 285:524-32. doi: 10.1111/joim.12886

18. Cui Y, Guo G. Immunomodulatory Function of the Tumor Suppressor p53 in Host Immune Response and the Tumor Microenvironment. Int J Mol Sci (2016) 17(11):1942. doi: 10.3390/ijms 17111942

19. Chen DS, Mellman I. Elements of cancer immunity and the cancer-immune set point. Nature (2017) 541:321-30. doi: 10.1038/nature21349

20. Albini A, Bruno A, Noonan DM, Mortara L. Contribution to Tumor Angiogenesis From Innate Immune Cells Within the Tumor Microenvironment: Implications for Immunotherapy. Front Immunol (2018) 9:527. doi: 10.3389/fimmu.2018.00527

21. Tugues S, Ducimetiere L, Friebel E, Becher B. Innate lymphoid cells as regulators of the tumor microenvironment. Semin Immunol (2019) 41:101270. doi: 10.1016/j.smim.2019.03.002

22. Ansems M, Span PN. The tumor microenvironment and radiotherapy response; a central role for cancer-associated fibroblasts. Clin Trans Radiat Oncol (2020) 22:90-7. doi: 10.1016/j.ctro.2020.04.001

23. Martinez-Zubiaurre I, Chalmers AJ, Hellevik T. Radiation-Induced Transformation of Immunoregulatory Networks in the Tumor Stroma. Front Immunol (2018) 9:1679. doi: 10.3389/fimmu.2018.01679

24. Tharmalingam H, Hoskin PJ. The optimism surrounding stereotactic body radiation therapy and immunomodulation. Chin Clin Oncol (2017) 6:S9. doi: $10.21037 / \mathrm{cco} .2017 .05 .01$

25. Kotera Y, Shimizu K, Mule JJ. Comparative analysis of necrotic and apoptotic tumor cells as a source of antigen(s) in dendritic cell-based immunization. Cancer Res (2001) 61:8105-9.

26. Barker HE, Paget JT, Khan AA, Harrington KJ. The tumour microenvironment after radiotherapy: mechanisms of resistance and recurrence. Nat Rev Cancer (2015) 15:409-25. doi: 10.1038/nrc3958

27. Jarosz-Biej M, Smolarczyk R, Cichon T, Kulach N. Tumor Microenvironment as A "Game Changer" in Cancer Radiotherapy. Int Mol Sci (2019) 20(13):3212. doi: 10.3390/ijms20133212 
28. Offersen BV, Alsner J, Nielsen HM, Jakobsen EH, Nielsen MH, Krause M, et al. Hypofractionated Versus Standard Fractionated Radiotherapy in Patients With Early Breast Cancer or Ductal Carcinoma In Situ in a Randomized Phase III Trial: The DBCG HYPO Trial. J Clin Oncol (2020) 38(31):3615-25. doi: 10.1200/JCO.20.01363

29. Oliinyk D, Augustin T, Koehler VF, Rauch J, Belka C, Spitzweg C, et al. Hypofractionated Radiotherapy for Anaplastic Thyroid Cancer: Systematic Review and Pooled Analysis. Cancers (Basel) (2020) 12(9):2506. doi: $10.3390 /$ cancers 12092506

30. Tamihardja J, Schortmann M, Lawrenz I, Weick S, Bratengeier K, Flentje M, et al. Moderately hypofractionated radiotherapy for localized prostate cancer: updated long-term outcome and toxicity analysis. Strahlenther Onkol (2020). doi: 10.1007/s00066-020-01678-w

31. Xing D, Siva S, Hanna GG. The Abscopal Effect of Stereotactic Radiotherapy and Immunotherapy: Fool's Gold or El Dorado? Clin Oncol (R Coll Radiol) (2019) 31:432-43. doi: 10.1016/j.clon.2019.04.006

32. Kim MS, Kim W, Park IH, Kim HJ, Lee E, Jung JH, et al. Radiobiological mechanisms of stereotactic body radiation therapy and stereotactic radiation surgery. Radiat Oncol J (2015) 33:265-75. doi: 10.3857/roj.2015.33.4.265

33. Brown JM, Carlson DJ, Brenner DJ. The tumor radiobiology of SRS and SBRT: are more than the 5 Rs involved? Int J Radiat Oncol Biol Phys (2014) 88:254-62. doi: 10.1016/j.ijrobp.2013.07.022

34. Eriksson D, Stigbrand T. Radiation-induced cell death mechanisms. Tumour Biol (2010) 31:363-72. doi: 10.1016/j.ijrobp.2013.07.022

35. Verheij M, Bartelink H. Radiation-induced apoptosis. Cell Tissue Res (2000) 301(1):133-42. doi: 10.1007/s004410000188

36. Sia J, Szmyd R, Hau E, Gee HE. Molecular Mechanisms of RadiationInduced Cancer Cell Death: A Primer. Front Cell Dev Biol (2020) 8:41. doi: $10.3389 / \mathrm{fcell} .2020 .00041$

37. Tesniere A, Panaretakis T, Kepp O, Apetoh L, Ghiringhelli F, Zitvogel L, et al. Molecular characteristics of immunogenic cancer cell death. Cell Death Differ (2008) 15(1):3-12. doi: 10.1038/sj.cdd.4402269

38. Moding EJ, Mowery YM, Kirsch DG. Opportunities for Radiosensitization in the Stereotactic Body Radiation Therapy (SBRT) Era. Cancer J (2016) 22:267-73. doi: 10.1097/PPO.0000000000000203

39. Schaue D, McBride WH. Opportunities and challenges of radiotherapy for treating cancer. Nat Rev Clin Oncol (2015) 12:527-40. doi: 10.1038/ nrclinonc. 2015.120

40. Diegeler S, Hellweg CE. Intercellular Communication of Tumor Cells and Immune Cells after Exposure to Different Ionizing Radiation Qualities. Front Immunol (2017) 8:664. doi: 10.3389/fimmu.2017.00664

41. Wattenberg MM, Fahim A, Ahmed MM, Hodge JW. Unlocking the combination: potentiation of radiation-induced antitumor responses with immunotherapy. Radiat Res (2014) 182:126-38. doi: 10.1667/RR13374.1

42. Frey B, Rubner Y, Kulzer L, Werthmoller N, Weiss EM, Fietkau R, et al. Antitumor immune responses induced by ionizing irradiation and further immune stimulation. Cancer Immunol Immunother (2014) 63:29-36. doi: $10.1007 / \mathrm{s} 00262-013-1474-y$

43. Gameiro SR, Jammeh ML, Wattenberg MM, Tsang KY, Ferrone S, Hodge JW. Radiation-induced immunogenic modulation of tumor enhances antigen processing and calreticulin exposure, resulting in enhanced T-cell killing. Oncotarget (2014) 5:403-16. doi: 10.18632/oncotarget.1719

44. Deng L, Liang H, Burnette B, Weicheslbaum RR, Fu YX. Radiation and antiPD-L1 antibody combinatorial therapy induces T cell-mediated depletion of myeloid-derived suppressor cells and tumor regression. Oncoimmunology (2014) 3:e28499. doi: 10.4161/onci.28499

45. Noman MZ, Hasmim M, Lequeux A, Xiao M, Duhem C, Chouaib S, et al. Improving Cancer Immunotherapy by Targeting the Hypoxic Tumor Microenvironment: New Opportunities and Challenges. Cells-Basel (2019) 8(9):1083. doi: 10.3390/cells8091083

46. Wu J, Chen J, Feng Y, Tian H, Chen X. Tumor microenvironment as the "regulator" and "target" for gene therapy. J Gene Med (2019) 21:e3088. doi: 10.1002/jgm.3088

47. Portella L, Scala S. Ionizing radiation effects on the tumor microenvironment. Semin Oncol (2019) 46:254-60. doi: 10.1053/j.seminoncol.2019.07.003

48. Junttila MR, de Sauvage FJ. Influence of tumour micro-environment heterogeneity on therapeutic response. Nature (2013) 501:346-54. doi: $10.1038 /$ nature 12626
49. Wu T, Dai Y. Tumor microenvironment and therapeutic response. Cancer Lett (2017) 387:61-8. doi: 10.1016/j.canlet.2016.01.043

50. Song CW, Lee YJ, Griffin RJ, Park I, Koonce NA, Hui S, et al. Indirect Tumor Cell Death After High-Dose Hypofractionated Irradiation: Implications for Stereotactic Body Radiation Therapy and Stereotactic Radiation Surgery. Int J Radiat Oncol Biol Phys (2015) 93:166-72. doi: 10.1016/j.ijrobp.2015. 05.016

51. Maeda A, Chen Y, Bu J, Mujcic H, Wouters BG, DaCosta RS. In Vivo Imaging Reveals Significant Tumor Vascular Dysfunction and Increased Tumor Hypoxia-Inducible Factor-1alpha Expression Induced by High Single-Dose Irradiation in a Pancreatic Tumor Model. Int J Radiat Oncol Biol Phys (2017) 97:184-94. doi: 10.1016/j.ijrobp.2016.09.005

52. Duan Q, Zhang H, Zheng J, Zhang L. Turning Cold into Hot: Firing up the Tumor Microenvironment. Trends Cancer (2020) 6:605-18. doi: 10.1016/ j.trecan.2020.02.022

53. Fan Z, Liu H, Xue Y, Lin J, Fu Y, Xia Z, et al. Reversing cold tumors to hot: An immunoadjuvant-functionalized metal-organic framework for multimodal imaging-guided synergistic photo-immunotherapy. Bioact Mater (2021) 6:312-25. doi: 10.1016/j.bioactmat.2020.08.005

54. Shimizu K, Iyoda T, Okada M, Yamasaki S, Fujii SI. Immune suppression and reversal of the suppressive tumor microenvironment. Int Immunol (2018) 30:445-54. doi: 10.1093/intimm/dxy042

55. Qian BZ, Pollard JW. Macrophage diversity enhances tumor progression and metastasis. Cell (2010) 141:39-51. doi: 10.1016/j.cell.2010.03.014

56. Chen J, Yao Y, Gong C, Yu F, Su S, Chen J, et al. CCL18 from tumorassociated macrophages promotes breast cancer metastasis via PITPNM3. Cancer Cell (2011) 19:541-55. doi: 10.1016/j.ccr.2011.02.006

57. Lee Y, Auh SL, Wang Y, Burnette B, Wang Y, Meng Y, et al. Therapeutic effects of ablative radiation on local tumor require $\mathrm{CD} 8+\mathrm{T}$ cells: changing strategies for cancer treatment. Blood (2009) 114:589-95. doi: 10.1182/ blood-2009-02-206870

58. Lugade AA, Sorensen EW, Gerber SA, Moran JP, Frelinger JG, Lord EM. Radiation-induced IFN-gamma production within the tumor microenvironment influences antitumor immunity. J Immunol (2008) 180:3132-9. doi: 10.4049/jimmunol.180.5.3132

59. Hennel R, Brix N, Seidl K, Ernst A, Scheithauer H, Belka C, et al. Release of monocyte migration signals by breast cancer cell lines after ablative and fractionated gamma-irradiation. Radiat Oncol (2014) 9:85. doi: 10.1186/ 1748-717X-9-85

60. Golden EB, Demaria S, Schiff PB, Chachoua A, Formenti SC. An abscopal response to radiation and ipilimumab in a patient with metastatic non-small cell lung cancer. Cancer Immunol Res (2013) 1:365-72. doi: 10.1158/23266066.CIR-13-0115

61. Gulley JL, Arlen PM, Bastian A, Morin S, Marte J, Beetham P, et al. Combining a recombinant cancer vaccine with standard definitive radiotherapy in patients with localized prostate cancer. Clin Cancer Res (2005) 11:3353-62. doi: 10.1158/1078-0432.CCR-04-2062

62. Garg AD, Nowis D, Golab J, Vandenabeele P, Krysko DV, Agostinis P. Immunogenic cell death, DAMPs and anticancer therapeutics: an emerging amalgamation. Biochim Biophys Acta (2010) 1805:53-71. doi: 10.1016/ j.bbcan.2009.08.003

63. Popp I, Grosu AL, Niedermann G, Duda DG. Immune modulation by hypofractionated stereotactic radiation therapy: Therapeutic implications. Radiother Oncol (2016) 120:185-94. doi: 10.1016/j.radonc.2016.07.013

64. Menon H, Ramapriyan R, Cushman TR, Verma V, Kim HH, Schoenhals JE, et al. Role of Radiation Therapy in Modulation of the Tumor Stroma and Microenvironment. Front Immunol (2019) 10:193. doi: 10.3389/ fimmu.2019.00193

65. Apetoh L, Ghiringhelli F, Tesniere A, Obeid M, Ortiz C, Criollo A, et al. Tolllike receptor 4-dependent contribution of the immune system to anticancer chemotherapy and radiotherapy. Nat Med (2007) 13:1050-9. doi: 10.1038/ $\mathrm{nm} 1622$

66. Yang Y, Liu B, Dai J, Srivastava PK, Zammit DJ, Lefrancois L, et al. Heat shock protein gp96 is a master chaperone for toll-like receptors and is important in the innate function of macrophages. Immunity (2007) 26:21526. doi: 10.1016/j.immuni.2006.12.005

67. Gupta A, Probst HC, Vuong V, Landshammer A, Muth S, Yagita H, et al. Radiotherapy promotes tumor-specific effector $\mathrm{CD} 8+\mathrm{T}$ cells via dendritic 
cell activation. J Immunol (2012) 189:558-66. doi: 10.4049/jimmunol. 1200563

68. Arnold KM, Flynn NJ, Raben A, Romak L, Yu Y, Dicker AP, et al. The Impact of Radiation on the Tumor Microenvironment: Effect of Dose and Fractionation Schedules. Cancer Growth Metastasis (2018) 11:1406729127. doi: 10.1177/1179064418761639

69. Peters HL, Yan Y, Solheim JC. APLP2 regulates the expression of MHC class I molecules on irradiated Ewing's sarcoma cells. Oncoimmunology (2013) 2: e26293. doi: 10.4161/onci.26293

70. Garnett CT, Palena C, Chakraborty M, Tsang KY, Schlom J, Hodge JW. Sublethal irradiation of human tumor cells modulates phenotype resulting in enhanced killing by cytotoxic T lymphocytes. Cancer Res (2004) 64:7985-94. doi: 10.1158/0008-5472.CAN-04-1525

71. Wennerberg E, Lhuillier C, Vanpouille-Box C, Pilones KA, Garcia-Martinez E, Rudqvist NP, et al. Barriers to Radiation-Induced In Situ Tumor Vaccination. Front Immunol (2017) 8:229. doi: 10.3389/fimmu.2017.00229

72. Tubin S, Popper HH, Brcic L. Novel stereotactic body radiation therapy (SBRT)-based partial tumor irradiation targeting hypoxic segment of bulky tumors (SBRT-PATHY): improvement of the radiotherapy outcome by exploiting the bystander and abscopal effects. Radiat Oncol (2019) 14:21. doi: 10.1186/s13014-019-1227-y

73. Tubin S, Yan W, Mourad WF, Fossati P, Khan MK. The future of radiationinduced abscopal response: beyond conventional radiotherapy approaches. Future Oncol (2020) 16:1137-51. doi: 10.2217/fon-2020-0063

74. Basler L, Andratschke N, Ehrbar S, Guckenberger M, Tanadini-Lang S. Modelling the immunosuppressive effect of liver SBRT by simulating the dose to circulating lymphocytes: an in-silico planning study. Radiat Oncol (2018) 13:10. doi: 10.1186/s13014-018-0952-y

75. Muroyama Y, Nirschl TR, Kochel CM, Lopez-Bujanda Z, Theodros D, Mao W, et al. Stereotactic Radiotherapy Increases Functionally Suppressive Regulatory T Cells in the Tumor Microenvironment. Cancer Immunol Res (2017) 5:9921004. doi: 10.1158/2326-6066.CIR-17-0040

76. Philippou Y, Sjoberg HT, Murphy E, Alyacoubi S, Jones KI, Gordon-Weeks $\mathrm{AN}$, et al. Impacts of combining anti-PD-L1 immunotherapy and radiotherapy on the tumour immune microenvironment in a murine prostate cancer model. Br J Cancer (2020) 123(7):1089-100. doi: 10.1038/ s41416-020-0956-x

77. Oweida AJ, Darragh L, Phan A, Binder D, Bhatia S, Mueller A, et al. STAT3 Modulation of Regulatory T Cells in Response to Radiation Therapy in Head and Neck Cancer. J Natl Cancer Inst (2019) 111:1339-49. doi: 10.1093/jnci/ djz036

78. Kachikwu EL, Iwamoto KS, Liao YP, DeMarco JJ, Agazaryan N, Economou $\mathrm{JS}$, et al. Radiation enhances regulatory $\mathrm{T}$ cell representation. Int $\mathrm{J}$ Radiat Oncol Biol Phys (2011) 81:1128-35. doi: 10.1016/j.jirobp.2010.09.034

79. Qinfeng S, Depu W, Xiaofeng Y, Shah W, Hongwei C, Yili W. In situ observation of the effects of local irradiation on cytotoxic and regulatory $\mathrm{T}$ lymphocytes in cervical cancer tissue. Radiat Res (2013) 179:584-9. doi: 10.1667/RR3155.1

80. Yang X, Lu Y, Hang J, Zhang J, Zhang T, Huo Y, et al. Lactate-modulated immunosuppression of myeloid-derived suppressor cells contributes to the radioresistance of pancreatic cancer. Cancer Immunol Res (2020) 8 (11):1440-51. doi: 10.1158/2326-6066.CIR-20-0111

81. Chen HY, Xu L, Li LF, Liu XX, Gao JX, Bai YR. Inhibiting the CD8(+) T cell infiltration in the tumor microenvironment after radiotherapy is an important mechanism of radioresistance. Sci Rep (2018) 8:11934. doi: 10.1038/s41598-018-30417-6

82. Hellevik T, Martinez-Zubiaurre I. Radiotherapy and the tumor stroma: the importance of dose and fractionation. Front Oncol (2014) 4:1. doi: 10.3389/ fonc.2014.00001

83. Begg K, Tavassoli M. Inside the hypoxic tumour: reprogramming of the DDR and radioresistance. Cell Death Discovery (2020) 6:77. doi: 10.1038/ s41420-020-00311-0

84. Wang Y, Liu ZG, Yuan H, Deng W, Li J, Huang Y, et al. The Reciprocity between Radiotherapy and Cancer Immunotherapy. Clin Cancer Res (2019) 25:1709-17. doi: 10.1158/1078-0432.CCR-18-2581

85. Sun X, Lv X, Yan Y, Zhao Y, Ma R, He M, et al. Hypoxia-mediated cancer stem cell resistance and targeted therapy. BioMed Pharmacother (2020) 130:110623. doi: 10.1016/j.biopha.2020.110623
86. Grabham P, Hu B, Sharma P, Geard C. Effects of ionizing radiation on threedimensional human vessel models: differential effects according to radiation quality and cellular development. Radiat Res (2011) 175:21-8. doi: 10.1667/ RR2289.1

87. Park HJ, Griffin RJ, Hui S, Levitt SH, Song CW. Radiation-induced vascular damage in tumors: implications of vascular damage in ablative hypofractionated radiotherapy (SBRT and SRS). Radiat Res (2012) 177:311-27. doi: 10.1667/rr2773.1

88. Sonveaux P, Brouet A, Havaux X, Gregoire V, Dessy C, Balligand JL, et al. Irradiation-induced angiogenesis through the up-regulation of the nitric oxide pathway: implications for tumor radiotherapy. Cancer Res (2003) 63:1012-9.

89. Sun X, Deng L, Lu Y. Challenges and opportunities of using stereotactic body radiotherapy with anti-angiogenesis agents in tumor therapy. Chin J Cancer Res (2018) 30:147-56. doi: 10.21147/j.issn.1000-9604.2018.01.15

90. Bhowmick NA, Neilson EG, Moses HL. Stromal fibroblasts in cancer initiation and progression. Nature (2004) 432:332-7. doi: 10.1038/nature03096

91. Kalluri R, Zeisberg M. Fibroblasts in cancer. Nat Rev Cancer (2006) 6:392401. doi: $10.1038 / \mathrm{nrc} 1877$

92. Orimo A, Weinberg RA. Stromal fibroblasts in cancer: a novel tumorpromoting cell type. Cell Cycle (2006) 5:1597-601. doi: 10.4161/cc.5.15.3112

93. Shimoda M, Mellody KT, Orimo A. Carcinoma-associated fibroblasts are a rate-limiting determinant for tumour progression. Semin Cell Dev Biol (2010) 21:19-25. doi: 10.1016/j.semcdb.2009.10.002

94. Liu L, Zhang Z, Zhou L, Hu L, Yin C, Qing D, et al. Cancer associated fibroblasts-derived exosomes contribute to radioresistance through promoting colorectal cancer stem cells phenotype. Exp Cell Res (2020) 391:111956. doi: 10.1016/j.yexcr.2020.111956

95. Hawsawi NM, Ghebeh H, Hendrayani SF, Tulbah A, Al-Eid M, Al-Tweigeri T, et al. Breast carcinoma-associated fibroblasts and their counterparts display neoplastic-specific changes. Cancer Res (2008) 68:2717-25. doi: 10.1158/00085472.CAN-08-0192

96. Papadopoulou A, Kletsas D. Human lung fibroblasts prematurely senescent after exposure to ionizing radiation enhance the growth of malignant lung epithelial cells in vitro and in vivo. Int J Oncol (2011) 39:989-99. doi: 10.3892/ijo.2011.1132

97. Tachiiri S, Katagiri T, Tsunoda T, Oya N, Hiraoka M, Nakamura Y. Analysis of gene-expression profiles after gamma irradiation of normal human fibroblasts. Int J Radiat Oncol Biol Phys (2006) 64:272-9. doi: 10.1016/ j.ijrobp.2005.08.030

98. Orimo A, Gupta PB, Sgroi DC, Arenzana-Seisdedos F, Delaunay T, Naeem R, et al. Stromal fibroblasts present in invasive human breast carcinomas promote tumor growth and angiogenesis through elevated SDF-1/CXCL12 secretion. Cell (2005) 121:335-48. doi: 10.1016/j.cell.2005.02.034

99. Tseng D, Vasquez-Medrano DA, Brown JM. Targeting SDF-1/CXCR4 to inhibit tumour vasculature for treatment of glioblastomas. $\mathrm{Br} J$ Cancer (2011) 104:1805-9. doi: 10.1038/bjc.2011.169

100. Gaggioli C, Hooper S, Hidalgo-Carcedo C, Grosse R, Marshall JF, Harrington $\mathrm{K}$, et al. Fibroblast-led collective invasion of carcinoma cells with differing roles for RhoGTPases in leading and following cells. Nat Cell Biol (2007) 9:1392-400. doi: 10.1038/ncb1658

101. Nguyen HQ, To NH, Zadigue P, Kerbrat S, De La Taille A, Le Gouvello S, et al. Ionizing radiation-induced cellular senescence promotes tissue fibrosis after radiotherapy. A review. Crit Rev Oncol Hematol (2018) 129:13-26. doi: 10.1016/j.critrevonc.2018.06.012

102. Rodier F, Coppe JP, Patil CK, Hoeijmakers WA, Munoz DP, Raza SR, et al. Persistent DNA damage signalling triggers senescence-associated inflammatory cytokine secretion. Nat Cell Biol (2009) 11:973-9. doi: $10.1038 /$ ncb1909

103. Piper M, Mueller AC, Karam SD. The interplay between cancer associated fibroblasts and immune cells in the context of radiation therapy. Mol Carcinog (2020) 59:754-65. doi: 10.1002/mc.23205

104. Hellevik T, Pettersen I, Berg V, Winberg JO, Moe BT, Bartnes K, et al. Cancer-associated fibroblasts from human NSCLC survive ablative doses of radiation but their invasive capacity is reduced. Radiat Oncol (2012) 7:59. doi: 10.1186/1748-717X-7-59

105. Ashrafizadeh M, Farhood B, Eleojo MA, Taeb S, Najafi M. The interactions and communications in tumor resistance to radiotherapy: Therapy 
perspectives. Int Immunopharmacol (2020) 87:106807. doi: 10.1016/ j.intimp.2020.106807

106. Bolli E, D’Huyvetter M, Murgaski A, Berus D, Stange G, Clappaert EJ, et al. Stromaltargeting radioimmunotherapy mitigates the progression of therapy-resistant tumors. J Control Release (2019) 314:1-11. doi: 10.1016/j.jconrel.2019.10.024

107. Gaipl US, Multhoff G, Pockley AG, Rodel F. Editorial: RadioimmunotherapyTranslational Opportunities and Challenges. Front Oncol (2020) 10:190. doi: $10.3389 /$ fonc. 2020.00190

108. Xu J, Escamilla J, Mok S, David J, Priceman S, West B, et al. CSF1R signaling blockade stanches tumor-infiltrating myeloid cells and improves the efficacy of radiotherapy in prostate cancer. Cancer Res (2013) 73:2782-94. doi: 10.1158/0008-5472.CAN-12-3981

109. Najafi M, Mortezaee K, Majidpoor J. Stromal reprogramming: A target for tumor therapy. Life Sci (2019) 239:117049. doi: 10.1016/j.lfs.2019.117049
110. Ciric E, Sersa G. Radiotherapy in combination with vascular-targeted therapies. Radiol Oncol (2010) 44:67-78. doi: 10.2478/v10019-010-002592293389

Conflict of Interest: The author declares that the research was conducted in the absence of any commercial or financial relationships that could be construed as a potential conflict of interest.

Copyright (c) 2021 Wang. This is an open-access article distributed under the terms of the Creative Commons Attribution License (CC BY). The use, distribution or reproduction in other forums is permitted, provided the original author(s) and the copyright owner(s) are credited and that the original publication in this journal is cited, in accordance with accepted academic practice. No use, distribution or reproduction is permitted which does not comply with these terms. 